\title{
Does grafting coronary arteries with only moderate stenosis affect long-term mortality?
}

\author{
Joseph F. Sabik III, MD, ${ }^{\mathrm{a}}$ Gabriel Olivares, MD, ${ }^{\mathrm{a}}$ Sajjad Raza, MD, ${ }^{\mathrm{a}}$ Bruce W. Lytle, MD, \\ Penny L. Houghtaling, MS, ${ }^{b}$ and Eugene H. Blackstone, MD ${ }^{a, b}$
}

\section{ABSTRACT}

Objective: Stenting coronary arteries with non-ischemia-producing moderate stenosis leads to worse outcomes than leaving them unstented. We sought to determine whether grafting coronary arteries with angiographically moderate stenosis is associated with worse long-term survival than leaving them ungrafted.

Methods: From 1972 to 2011, 55,567 patients underwent primary isolated coronary artery bypass grafting $(\mathrm{CABG}) ; 8531$ had a single coronary artery with moderate (50\%-69\%) stenosis, bypassed in $6598(77 \%)$ and not bypassed in $1933(23 \%)$. These arteries were grafted with internal thoracic arteries (ITAs) in 1806 patients $(27 \%)$ and with saphenous veins (SVs) in $4625(70 \%)$ Mean follow-up for all-cause mortality was $13.0 \pm 9.7$ years.

Results: Survival was similar for patients with and without a graft to the moderately stenosed coronary artery $(P=.3): 97 \%, 76 \%, 43 \%$, and $18 \%$ at 1 , 10,20 , and 30 years among patients receiving no graft; $97 \%, 74 \%, 41 \%$, and $18 \%$ among those receiving an SV graft; and 98\%, 82\%, 51\%, and $23 \%$ among those receiving an ITA graft. After adjusting for patient characteristics, SV grafting versus nongrafting of moderately stenosed coronary arteries was associated with similar long-term mortality $(P=.2)$, whereas ITA grafting was associated with $22 \%$ lower long-term mortality (hazard ratio $0.78 ; 68 \%$ confidence interval $0.75-0.82 ; P<.0001)$.

Conclusions: Grafting coronary arteries with angiographically moderate stenosis is not harmful. Instead, ITA grafting of such coronary arteries is associated with lower long-term mortality. Thus, after placing the first ITA to the left anterior descending, the second ITA should be placed to the second most important coronary artery, even if it is moderately stenosed. (J Thorac Cardiovasc Surg 2016;151:806-11)

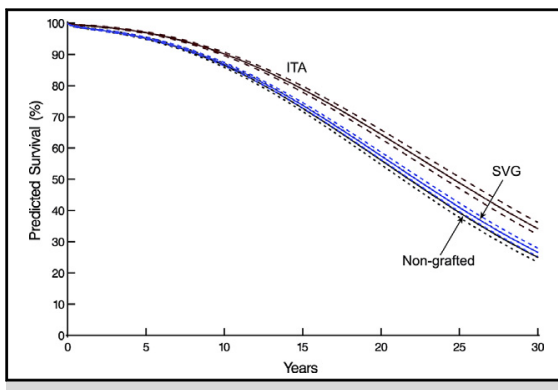

Survival after ITA versus SV grafting versus no grafting of moderately stenosed coronary arteries.

\section{Central Message}

Grafting moderately stenosed coronary arteries is not harmful. Internal thoracic artery grafting of such arteries is associated with lower late mortality.

\section{Perspective}

Internal thoracic artery (ITA) grafting of coronary arteries with angiographically moderate stenosis is associated with lower long-term mortality. Therefore, after placing the first ITA to the left anterior descending coronary artery, the second ITA should be used to graft the next most important coronary artery, even if it is only moderately stenosed.

See Editorial Commentary page 812 .

See Editorial page 300 in the February issue.
Stenting coronary arteries with non-ischemia-producing moderate stenosis leads to worse outcomes than leaving them unstented. ${ }^{1-3}$ Although an ischemia-guided approach yields better percutaneous coronary intervention (PCI)

From the ${ }^{\mathrm{a}}$ Department of Thoracic and Cardiovascular Surgery, Heart and Vascular Institute, Cleveland Clinic, Cleveland, Ohio; and ${ }^{\mathrm{b}}$ Department of Quantitative Health Sciences, Research Institute, Cleveland Clinic, Cleveland, Ohio.

Funding Support: This study was funded in part by the Cleveland Clinic Department of Thoracic and Cardiovascular Surgery, the Gus P. Karos Registry Fund, the Sheikh Hamdan bin Rashid Al Maktoum Distinguished Chair in Thoracic and Cardiovascular Surgery (held by Dr Sabik), and the Kenneth Gee and Paula Shaw, $\mathrm{PhD}$, Chair in Heart Research (held by Dr Blackstone).

Read at the 95th Annual Meeting of The American Association for Thoracic Surgery, Seattle, Washington, April 25-29, 2015. outcomes than the traditional angiographically guided approach, $^{1-3}$ its value in patients undergoing coronary artery bypass grafting (CABG) is unknown. Most angiographically moderate coronary stenoses would not

Received for publication April 28, 2015; revisions received Oct 1, 2015; accepted for publication Oct 10, 2015; available ahead of print Nov 19, 2015.

Address for reprints: Joseph F. Sabik III, MD, Department of Thoracic and Cardiovascular Surgery, Cleveland Clinic, 9500 Euclid Ave/Desk J4-1, Cleveland, OH 44195 (E-mail: sabikj@ccf.org).

0022-5223/\$36.00

Copyright (C) 2016 Published by Elsevier Inc. on behalf of The American Association for Thoracic Surgery

http://dx.doi.org/10.1016/j.jtcvs.2015.10.021 

Abbreviations and Acronyms
$\mathrm{CABG}=$ coronary artery bypass grafting
$\mathrm{CAD}=$ coronary artery disease
$\mathrm{CL}=$ confidence limit
FFR = fractional flow reserve
ITA $=$ internal thoracic artery
IVUS $=$ intravascular ultrasound
LAD = left anterior descending coronary artery
LCx = left circumflex coronary artery
PCI = percutaneous coronary intervention
RCA = right coronary artery
$\mathrm{SV}=$ saphenous vein

Scanning this QR code will take you to supplemental data for this article.

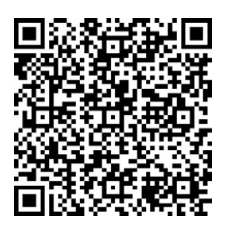

be identified by an ischemia-guided approach as candidates for revascularization, yet traditionally, surgeons have attempted to bypass all such lesions. Therefore, we sought to determine whether grafting coronary arteries with moderate anatomic stenosis is associated with poorer long-term mortality than leaving them ungrafted.

\section{PATIENTS AND METHODS}

From 1972 to 2011, 55,567 patients underwent primary isolated CABG at Cleveland Clinic. Of these, 8531 had a single coronary artery with angiographically moderate $(50 \%-69 \%)$ stenosis as defined by expert cardiologists, bypassed in 6598 patients (77\%) and not bypassed in 1933 $(23 \%)$. These patients had bypasses to all other coronary arteries with severe $(\geq 70 \%)$ stenoses. Moderate stenosis was present in the circumflex artery in 2714 patients (32\%), right coronary artery (RCA) in 2599 (30\%), diagonals in $1635(19 \%)$, and left anterior descending coronary artery (LAD) in $1583(19 \%$; Table 1). Internal thoracic arteries (ITA) were used to graft moderately stenosed coronary arteries in 1806 patients $(27 \%)$, and saphenous vein (SV) grafts were used in $4625(70 \%)$. Most ITA grafts went to the LAD, followed by diagonals and the left circumflex (LCx) coronary artery, and most SV grafts went to the RCA, followed by the LCx and diagonals (Table E1).

Patients with multiple systems of moderate stenosis, left main disease with $\geq 50 \%$ stenosis, any bypassed lesion with $<50 \%$ stenosis, incomplete revascularization of coronary systems with $\geq 70 \%$ stenosis, or previous PCI were excluded from the study. Our rationale for this study design was that if multiple moderately stenosed arteries were present, the analysis would be confounded, particularly if each moderately stenosed lesion was managed differently, as also would be the case if severely stenosed coronary arteries were not grafted. Thus, we studied a single moderately stenosed coronary artery in isolation of these confounding factors.

Patients were identified and preoperative, operative, and postoperative variables (Appendix E1) retrieved from the prospective Cleveland Clinic Cardiovascular Information Registry. This database is populated concurrently with patient care and has been approved for use in research by the Cleveland Clinic Institutional Review Board, with patient consent waived.

\section{Endpoint}

The endpoint of this study was long-term mortality. Vital status after hospital discharge was obtained by routine anniversary follow-up questionnaires supplemented with data from the Social Security Death Master File, ${ }^{4,5}$ accessed on October 27, 2011, with a closing date of April 27, 2011. A total of 112,051 patient-years of follow-up data were available for analyses. Mean follow-up was $13 \pm 9.7$ years (median, 12 years), with $25 \%$ of survivors followed for more than 22 years and $10 \%$ for more than 29 years.

\section{Data Analysis}

Long-term survival. Survival was assessed nonparametrically by using the Kaplan-Meier method ${ }^{6}$ and parametrically by using a multiphase hazard model. ${ }^{7}$ The latter involved resolving the number of hazard phases for instantaneous risk of death (hazard function) and estimating shaping parameters (for details, see www.lerner.ccf.org/qhs/software/hazard). Survival estimates with associated $68 \%$ confidence limits (CLs) were plotted for selected time points for the bypass groups and by location of moderate stenosis.

Risk adjustment. Multivariable analysis was performed in the hazard function domain by using the parametric multiphase hazard model, with factors modulating both hazard phases considered simultaneously.

Variables considered in the analysis are listed in Appendix E1. Variable selection, with a $P$-value criterion for retention of variables in the model of .05 , used the machine-learning "bagging" method (bootstrap

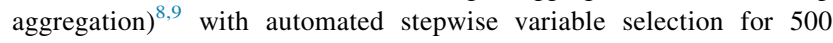
bootstrap data sets, followed by assessment of the frequency of occurrence of variables in these models. Those appearing in $50 \%$ or more of the models were retained in the final model. Variables related to management of the moderate coronary artery disease (CAD) were examined closely. Although none of these met the $50 \%$ reliability criterion for variable selection, we forced into the model the type of graft and whether the moderate systems were bypassed or not.

Missing values. A number of variables examined in multivariable analyses had missing values. We used fivefold multiple imputation ${ }^{10}$ with a Markov chain Monte Carlo technique to impute missing values (SAS PROC MI; SAS Institute, Cary, NC). In multivariable modeling, for each imputed complete data set, we estimated regression coefficients and their variance-covariance matrix. Then, following Rubin, ${ }^{10}$ we combined estimates from the 5 models (SAS PROC MIANALYZE) to yield final regression coefficient estimates, the variance-covariance matrix, and $P$ values.

Presentation. Categorical data are summarized by frequencies and percentages; comparisons were made using the $\chi^{2}$ test or Fisher's exact test when frequency was less than 5 . Continuous variables are summarized as mean \pm standard deviation, or as 15 th, 50th (median), and 85th percentiles when data are skewed; comparisons were made using the Wilcoxon rank-sum test. Uncertainty is expressed by CLs equivalent to \pm 1 standard error $(68 \%)$. All analyses were performed using SAS statistical software (SAS version 9.2).

\section{RESULTS}

\section{Patient Characteristics}

Most baseline patient characteristics were similar in patients with grafted moderately stenosed coronary arteries and those with nongrafted moderately stenosed coronary 
TABLE 1. Patient characteristics stratified by nongrafted versus grafted moderate CAD

\begin{tabular}{|c|c|c|c|c|c|}
\hline \multirow[b]{2}{*}{ Characteristic } & \multicolumn{2}{|c|}{ Not grafted, $n=1933$} & \multicolumn{2}{|c|}{ Grafted, $n=6598$} & \multirow[b]{2}{*}{$\boldsymbol{P}$} \\
\hline & $\mathbf{n}^{*}$ & No. $(\%)$ or mean \pm SD & $\mathbf{n}^{*}$ & No. $(\%)$ or mean \pm SD & \\
\hline \multicolumn{6}{|l|}{ Demography } \\
\hline Age, y & 1933 & $59 \pm 10$ & 6598 & $60 \pm 10$ & $<.0001$ \\
\hline Female & 1933 & $350(18)$ & 6598 & $1299(20)$ & .12 \\
\hline \multicolumn{6}{|l|}{ Race } \\
\hline Black & 1669 & $46(2.8)$ & 6401 & $97(3.1)$ & .5 \\
\hline White & 1669 & $1536(92)$ & 6401 & $5876(92)$ & .8 \\
\hline Body mass index, $\mathrm{kg} \cdot \mathrm{m}^{-2}$ & 942 & $28 \pm 4.8$ & 4360 & $28 \pm 4.6$ & .06 \\
\hline \multicolumn{6}{|l|}{ Symptoms } \\
\hline NYHA functional class & 1923 & & 6587 & & $<.0001$ \\
\hline I & & $285(15)$ & & 1267 (19) & \\
\hline II & & 705 (37) & & $2506(38)$ & \\
\hline III & & $225(12)$ & & $675(10)$ & \\
\hline IV & & 708 (37) & & $2139(32)$ & \\
\hline Emergency operation & 1933 & 31 (1.6) & 6598 & $49(0.74)$ & .0006 \\
\hline \multicolumn{6}{|l|}{ Cardiac comorbidities } \\
\hline Prior myocardial infarction & 1933 & $917(47)$ & 6598 & $3244(49)$ & .18 \\
\hline Atrial fibrillation or flutter & 1442 & $16(1.1)$ & 5458 & $71(1.3)$ & .6 \\
\hline Heart failure & 1933 & $113(5.8)$ & 6598 & $331(5.0)$ & .15 \\
\hline \multicolumn{6}{|l|}{ Noncardiac comorbidities } \\
\hline History of smoking & 1829 & $971(53)$ & 6423 & $3371(52)$ & 6 \\
\hline Stroke & 1933 & $61(3.2)$ & 6598 & $296(4.5)$ & .01 \\
\hline Carotid artery disease & 1933 & $158(8.2)$ & 6598 & $572(8.7)$ & .5 \\
\hline Peripheral vascular disease & 1933 & $190(9.8)$ & 6598 & $640(9.7)$ & .9 \\
\hline Pharmacologically treated diabetes & 1851 & $330(18)$ & 6321 & $1149(18)$ & .7 \\
\hline Bilirubin, $\mathrm{mg} \cdot \mathrm{dL}^{-1}$ & 526 & $0.69 \pm 1.01$ & 2294 & $0.62 \pm 0.41$ & .7 \\
\hline Creatinine, $\mathrm{mg} \cdot \mathrm{dL}^{-1}$ & 588 & $1.2 \pm 0.71$ & 2547 & $1.2 \pm 0.89$ & .4 \\
\hline Blood urea nitrogen, $\mathrm{mg} \cdot \mathrm{dL}^{-1}$ & 587 & $19 \pm 8.5$ & 2552 & $19 \pm 10$ & .3 \\
\hline Cholesterol, $\mathrm{mg} \cdot \mathrm{dL}^{-1}$ & 1445 & $232 \pm 59$ & 5015 & $229 \pm 55$ & .05 \\
\hline Triglycerides, $\mathrm{mg} \cdot \mathrm{dL}^{-1}$ & 1219 & $191 \pm 122$ & 4266 & $185 \pm 128$ & .002 \\
\hline Hematocrit, $\%$ & 543 & $39 \pm 5.9$ & 2354 & $40 \pm 5.1$ & .02 \\
\hline \multicolumn{6}{|l|}{ Coronary anatomy } \\
\hline No. of systems diseased $\dagger$ & 1933 & & 6598 & & $<.0001$ \\
\hline 1 & & $49(2.5)$ & & $172(2.6)$ & \\
\hline 2 & & $606(31)$ & & $1710(26)$ & \\
\hline 3 & & $1278(66)$ & & $4716(71)$ & \\
\hline No. of systems diseased $\ddagger$ & 1933 & & 6598 & & $<.0001$ \\
\hline 0 & & $1(0.05)$ & & $82(1.2)$ & \\
\hline 1 & & $503(26)$ & & $1536(23)$ & \\
\hline 2 & & $1029(53)$ & & $4298(65)$ & \\
\hline 3 & & $400(21)$ & & $682(10)$ & \\
\hline \multicolumn{6}{|l|}{ Moderate $\mathrm{CAD} \S$} \\
\hline In right coronary artery & 1933 & $654(34)$ & 6598 & $1945(29)$ & .0003 \\
\hline In left anterior descending & 1933 & $121(6.3)$ & 6598 & $1462(22)$ & $<.0001$ \\
\hline In left circumflex & 1933 & $559(29)$ & 6598 & $2155(33)$ & .002 \\
\hline In diagonal & 1933 & $599(31)$ & 6598 & $1036(16)$ & $<.0001$ \\
\hline
\end{tabular}

SD, Standard deviation; NYHA, New York Heart Association; CAD, coronary artery disease. *Patients with data available. $\dagger \geq 50 \%$ stenosis. $\ddagger \geq 70 \%$ stenosis. $\S 50 \%-69 \%$ stenosis.

arteries (Table 1). However, more patients in the nongrafted group had slightly higher triglyceride levels $(191 \pm 122$ vs $185 \pm 128)$ and underwent emergency operation (1.6\% vs $0.74 \%$ ), whereas more patients in the grafted group had 3 -system CAD ( $71 \%$ vs $66 \%)$ than their nongrafted counterparts.

\section{Survival}

Survival was similar for patients with and without a graft to the moderately stenosed coronary artery $(P=.3$; Figure $1, A$ ). Survival at $1,5,10,20$, and 30 years was $97 \%, 90 \%, 76 \%, 43 \%$, and $18 \%$ in patients receiving no graft to moderately stenosed coronary arteries; $97 \%$, 


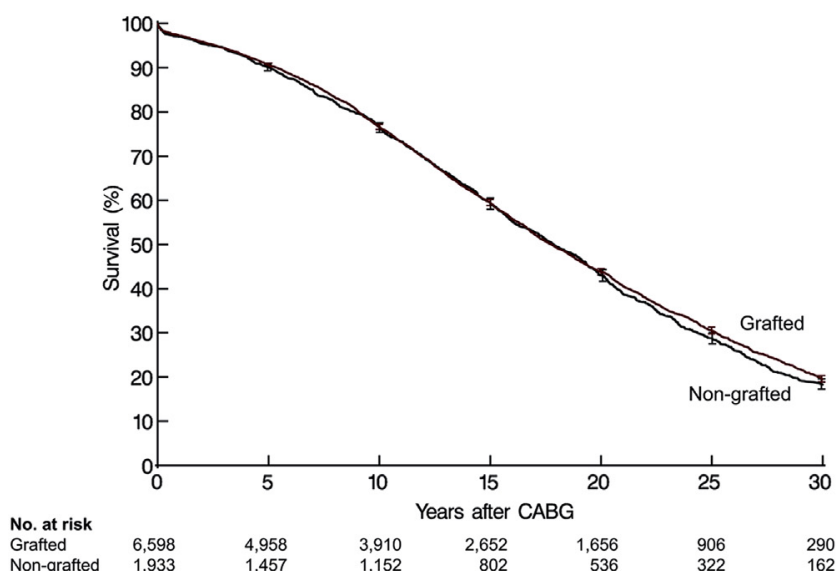

A

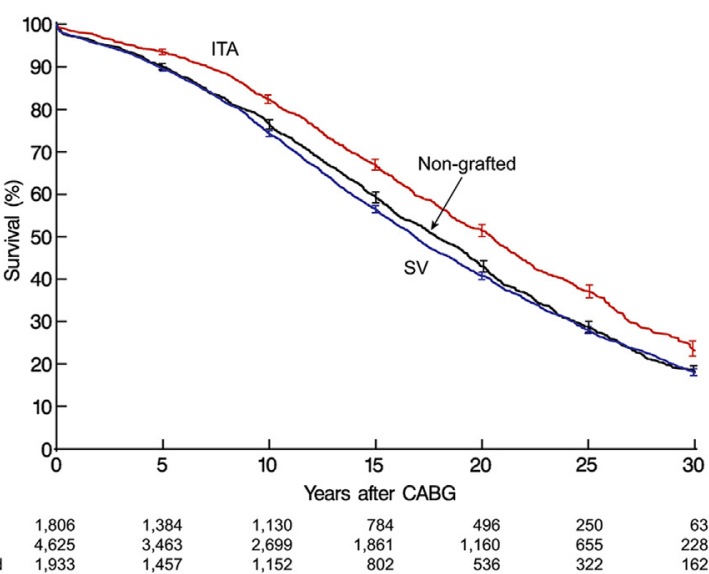

B

FIGURE 1. Unadjusted long-term survival in patients undergoing coronary artery bypass grafting $(C A B G)$ with 1 moderately stenosed artery $(\mathrm{n}=8531)$. Curves are Kaplan-Meier estimates with associated 68\% confidence limits (vertical bars). A, Stratified by grafted versus nongrafted artery. B, Stratified by internal thoracic artery (ITA) grafting versus saphenous vein $(S V)$ grafting versus nongrafting of artery.

$89 \%, 74 \%, 41 \%$, and $18 \%$ in those receiving $\mathrm{SV}$ grafts; and $98 \%, 93 \%, 82 \%, 51 \%$, and $23 \%$ in those receiving ITA grafts (Figure $1, B$ ). Among the 5171 patients receiving an ITA graft to a severely stenosed LAD, longterm survival was better if the moderately stenosed non-LAD coronary was grafted with the second ITA instead of an SV graft or if no graft was used (Figure E1).

\section{Risk-Adjusted Survival}

After adjusting for patient characteristics, early mortality was similar for patients with and without a graft to a moderately stenosed coronary artery $(P=.3$; Figure $2, A$; Tables 2 and E2), but late mortality was $11 \%$ lower in patients with a graft to the moderately stenosed coronary artery $(P=.003)$. SV grafting versus nongrafting of moderately stenosed coronary arteries was associated with similar early and late mortality (early $P=.8$; late $P=.2$ ), whereas ITA grafting versus nongrafting of such arteries was associated with 53\% lower early mortality and 22\% lower long-term mortality (early $P=.0001$; late $P<.0001$; Figure $2, B$ and Tables 3 and E3).
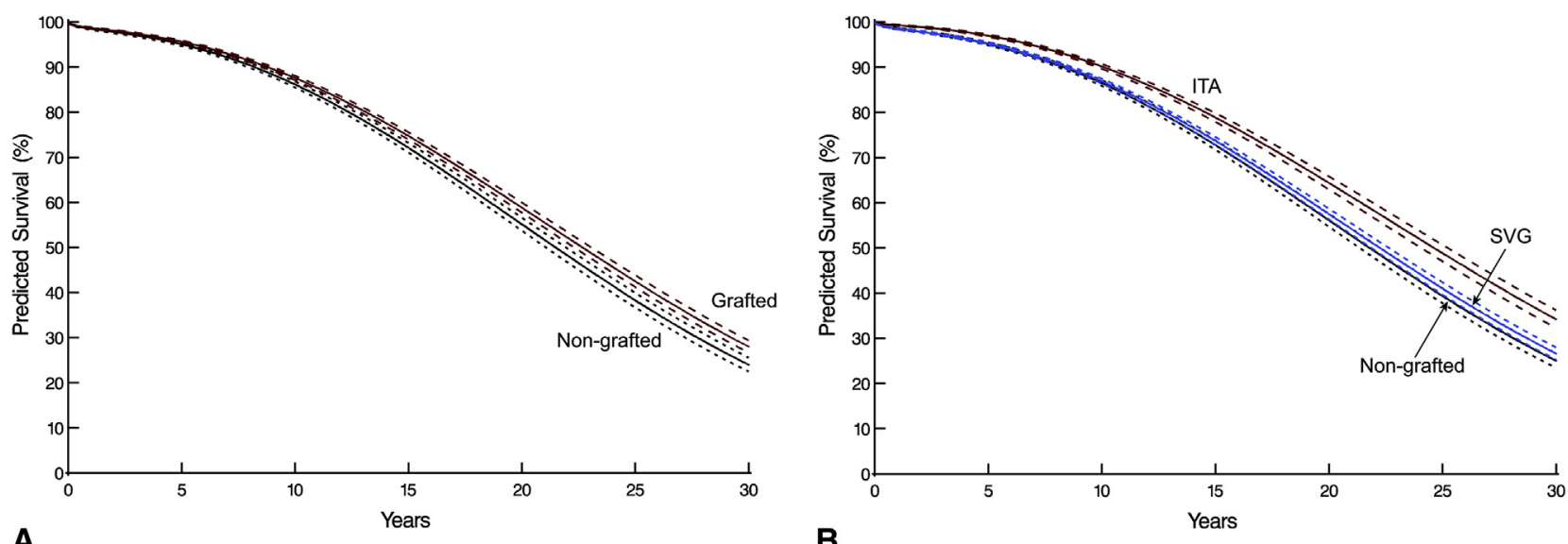

FIGURE 2. Adjusted long-term survival in patients undergoing coronary artery bypass grafting (CABG) with 1 moderately stenosed coronary artery. Solid lines are parametric estimates enclosed within $68 \%$ dashed confidence limits. Panel (A) is a nomogram of the multivariable equation in Table E1 and panel (B) is a nomogram of the multivariable equation in Table E2 for a patient with the following characteristics: age $=60$ years, body mass index $=28 \mathrm{~kg} \cdot \mathrm{m}^{-2}$, weight $=80 \mathrm{~kg}$, no previous stroke, no heart failure, no peripheral vascular disease, no history of smoking, no diabetes, no prior myocardial infarction, New York Heart Association functional class II, triglycerides $=180 \mathrm{mg} \cdot \mathrm{dL}^{-1}$, number of internal thoracic artery grafts to vessel with severe stenosis $(\geq 70 \%)=1$, number of diseased coronary systems $=3$. A, Stratified by grafting versus nongrafting of artery. B, Stratified by internal thoracic artery (ITA) grafting versus saphenous vein grafting $(S V G)$ versus nongrafting of artery. 
TABLE 2. Effect of grafting versus nongrafting of moderately stenosed coronary arteries $(\mathbf{n}=\mathbf{8 5 3 1})$

\begin{tabular}{|c|c|c|c|}
\hline Factor & Coefficient $\pm \mathrm{SE}$ & $\begin{array}{c}\text { Hazard ratio } \\
\text { (95\% CLs) }\end{array}$ & $P$ \\
\hline \multicolumn{4}{|l|}{ Early phase* } \\
\hline Moderate CAD bypassed & $-0.128 \pm 0.135$ & $0.88(0.67-1.15)$ & .3 \\
\hline Moderate CAD bypassed & $-0.114 \pm 0.038$ & $0.89(0.83-0.96)$ & \\
\hline
\end{tabular}

Reference group: moderate CAD not grafted. $S E$, Standard error; $C L$, confidence limits; $C A D$, coronary artery disease. *After adjusting for age, body mass index, weight, New York Heart Association functional class, previous myocardial infarction, heart failure, elevated triglycerides, peripheral vascular disease, stroke, treated diabetes, history of smoking, number of coronary artery systems diseased, emergency operation, and internal thoracic artery grafting of coronary arteries with severe $(\geq 70 \%)$ stenosis (see Table E1).

\section{DISCUSSION \\ Principal Findings}

This study demonstrates that grafting coronary arteries with angiographically moderate stenosis was not harmful. $\mathrm{SV}$ grafting versus nongrafting of moderate lesions was associated with similar long-term survival, and ITA grafting of such lesions was associated with better long-term survival.

\section{Findings in Context}

Stenting coronary arteries with non-ischemia-producing moderate stenosis leads to worse outcomes than leaving them unstented. ${ }^{1,2}$ Our study shows that grafting coronary arteries with angiographically moderate stenosis is not harmful, whereas ITA grafting of such lesions is beneficial. The explanation for these contrasting findings between stenting and grafting may lie in the fundamental differences between revascularization achieved by PCI

TABLE 3. Effect of internal thoracic artery and saphenous vein grafting versus nongrafting of moderately stenosed coronary arteries $(\mathbf{n}=\mathbf{8 5 3 1})$

\begin{tabular}{lccc}
\hline \multicolumn{1}{c}{ Factor } & Coefficient \pm SE & $\begin{array}{c}\text { Hazard ratio } \\
(\mathbf{9 5} \% \mathbf{C L s})\end{array}$ & $\boldsymbol{P}$ \\
\hline $\begin{array}{l}\text { Early phase* } \\
\text { ITA graft to moderate }\end{array}$ & $-0.76 \pm 0.20$ & $0.47(0.32-0.69)$ & .0001 \\
$\quad$ CAD & & & \\
$\quad \begin{array}{l}\text { SV graft to moderate } \\
\quad \text { CAD }\end{array}$ & $0.0088 \pm 0.034$ & $1.01(0.94-1.08)$ & .8 \\
$\begin{array}{l}\text { Late phase* } \\
\text { ITA graft to moderate } \\
\quad \text { CAD }\end{array}$ & $-0.242 \pm 0.051$ & $0.78(0.71-0.87)$ & $<.0001$ \\
$\quad \begin{array}{l}\text { SV graft to moderate } \\
\text { CAD }\end{array}$ & $-0.047 \pm 0.039$ & $0.95(0.88-1.03)$ & .2 \\
\hline
\end{tabular}

Reference group: moderate CAD not grafted. $S E$, Standard error; $C L$, confidence limits; ITA, internal thoracic artery; $C A D$, coronary artery disease; $S V$, saphenous vein. *After adjusting for age, body mass index, weight, New York Heart Association functional class, previous myocardial infarction, heart failure, elevated triglycerides, peripheral vascular disease, stroke, treated diabetes, history of smoking, number of coronary artery systems diseased, emergency operation, and internal thoracic artery grafting of coronary arteries with severe $(\geq 70 \%)$ stenosis (see Table E2). and revascularization achieved by CABG. First, thrombosis or early restenosis in a stent can lead to myocardial ischemia and infarction, ${ }^{1}$ whereas grafting a moderate lesion may lead only to early graft closure with preserved antegrade blood flow from the patent coronary artery, resulting in no harm to the patient. Second, PCI treats lesions as they exist at the time of the procedure, relying in the long term on the coronary artery to remain patent distal to the stent. We know that beyond 1 year after stenting, new events result almost exclusively from the progression of disease in segments other than the stented lesion. ${ }^{11}$ Compared with PCI, CABG brings a second source of blood flow to the distal coronary artery that, if it remains patent, is independent of possible proximal plaque rupture that may occur with time. It is important to note that moderate lesions tend to be the culprits because their acute thrombosis can lead to myocardial infarction. ${ }^{12}$ Therefore, a patent graft to a moderately stenosed coronary artery might be protective in the long run. Hayward and colleagues ${ }^{13}$ showed that at 8 years, $83 \%$ of grafts to moderately stenosed left-sided lesions, and at 7 years, $73 \%$ of grafts to moderately stenosed right-sided lesions, remain patent. Therefore, in weighing the risks and benefits of grafting versus nongrafting of a moderate lesion, the balance lies in favor of grafting.

Studies from the 1970s of the natural history of CAD also showed that survival is better in patients with fewer coronary arteries with $\geq 50 \%$ stenosis, demonstrating that $50 \%$ stenosis does influence survival. ${ }^{14}$ One reason patients are referred for CABG is that, traditionally, it has offered more complete revascularization than PCI. There is evidence that incomplete revascularization based on $\geq 50 \%$ stenosis determined by angiography is associated with decreased long-term survival. ${ }^{15,16}$

Grafting the LAD (irrespective of the degree of stenosis $\geq 50 \%$ ) with an ITA is the gold standard of primary coronary surgery. Our study shows that grafting moderate lesions with an ITA is associated with better long-term survival than SV grafting or nongrafting. Given this, the most important clinical implication for surgeons that can be derived from the results of this study is that once the first ITA has been placed to the LAD, the second ITA should be used to graft the next most important coronary artery, which is usually the LCx, even if it is only moderately stenosed. Our previously published paper on competitive flow also showed that "Internal thoracic artery patency decreases as coronary competitive flow increases. However, the nature of this relationship indicates ITAs should not be abandoned at moderate grades of stenosis." 17

\section{Ischemia-driven revascularization}

In $\mathrm{CABG}$, use of fractional flow reserve (FFR), which evaluates the potential of a coronary artery to induce myocardial ischemia, is rare. Studies evaluating FFR versus 
angiographically guided $\mathrm{CABG}$ have few patients and a short follow-up of 3 years or less. ${ }^{18}$ Also, this technique of assessing the potential of a coronary artery to induce myocardial ischemia has limitations. The experimental basis of FFR assumes normal distal microcirculation ${ }^{19}$; however, this may not be true for patients with diffuse coronary disease or diabetes, who may have small-vessel disease distal to the tip of the pressure-measuring device, and this is the patient population mostly referred for surgery. The usefulness of FFR in the setting of bifurcation lesions and poor response to coronary vasodilators, such as patients with left ventricular hypertrophy, also requires further evaluation. ${ }^{20}$

\section{Limitations}

First, this was an observational, nonrandomized, comparative effectiveness study, and patient factors might have influenced our findings. To account for this, we performed multivariable risk adjustment, but any patient factors not included in the analysis that could affect mortality might have biased our findings. Second, this was a single-center study, and findings may not be generalizable. Third, because 4 decades of data were used for analyses, applicability of these results to contemporary patients could be questioned. For this, we adjusted for the date of operation in our multivariable model. Fourth, in part we used the Social Security Death Master File for long-term follow-up, which provides only all-cause mortality. Therefore, we do not know whether deaths in our study were cardiac or noncardiac related. Fifth, we were unable to do separate subset analyses for each coronary system because the numbers were too small for meaningful comparisons. Sixth, we did not have coronary intravascular ultrasound (IVUS) or FFR data for the patients in the study. IVUS was not generally used to quantify stenosis, and FFR came into common use just recently. Seventh, our stenosis data are based on qualitative angiography and not quantitative angiography. Although quantitative coronary angiography is more reproducible, it is time-consuming and expensive. Given that we have more than 8500 patients in the study, retrospective quantitative analysis was not feasible. More importantly, clinical decision making is virtually always based on qualitative and not quantitative angiography. Therefore, qualitative angiography represents the real-world approach.

\section{CONCLUSIONS}

Grafting coronary arteries with angiographically moderate stenosis is not harmful. Instead, ITA grafting of such coronary arteries is associated with lower long-term mortality. Therefore, after placing the first ITA to the LAD, the second ITA should be placed to the second most important coronary artery, even if it is only moderately stenosed.

\section{Conflict of Interest Statement}

Dr Sabik is the North American principal investigator for the Abbott Laboratories-sponsored left main coronary disease randomized trial (EXCEL), is on the Society for Thoracic Surgeons board of directors, and is on the scientific advisory board of Medtronic. All other authors have nothing to disclose with regard to commercial support.

\section{References}

1. Tonino PA, De Bruyne B, Pijls NH, Siebert U, Ikeno F, van't Veer M, et al Fractional flow reserve versus angiography for guiding percutaneous coronary intervention. N Engl J Med. 2009;360:213-24.

2. Pijls NH, van Schaardenburgh P, Manoharan G, Boersma E, Bech JW, van't Veer M, et al. Percutaneous coronary intervention of functionally nonsignificant stenosis: 5-year follow-up of the DEFER Study. J Am Coll Cardiol. 2007;49:2105-11.

3. Zhang D, Lv S, Song X, Yuan F, Xu F, Zhang M, et al. Fractional flow reserve versus angiography for guiding percutaneous coronary intervention: a meta-analysis. Heart. 2015;101:455-62.

4. Boyle CA, Decoufle P. National sources of vital status information: extent of coverage and possible selectivity in reporting. Am J Epidemiol. 1990;131:160-8.

5. Newman TB, Brown AN. Use of commercial record linkage software and vital statistics to identify patient deaths. J Am Med Inform Assoc. 1997;4:233-7.

6. Kaplan EL, Meier P. Nonparametric estimation from incomplete observations. J Am Stat Assoc. 1958;53:457-81

7. Blackstone EH, Naftel DC, Turner ME Jr. The decomposition of time-varying hazard into phases, each incorporating a separate stream of concomitant information. J Am Stat Assoc. 1986;81:615-24.

8. Breiman L. Bagging predictors. Machine Learning. 1996;24:123-40.

9. Sauerbrei W, Schumacher M. A bootstrap resampling procedure for model building: application to the Cox regression model. Stat Med. 1992;11:2093-109.

10. Rubin DB. Multiple Imputation for Non-Response in Surveys. New York: Wiley; 1987.

11. Cutlip DE, Chhabra AG, Baim DS, Chauhan MS, Marulkar S, Massaro J, et al Beyond restenosis: five-year clinical outcomes from second-generation coronary stent trials. Circulation. 2004;110:1226-30.

12. Casscells W, Naghavi M, Willerson JT. Vulnerable atherosclerotic plaque: a multifocal disease. Circulation. 2003;107:2072-5.

13. Hayward PA, Zhu YY, Nguyen TT, Hare DL, Buxton BF. Should all moderate coronary lesions be grafted during primary coronary bypass surgery? An analysis of progression of native vessel disease during a randomized trial of conduits. J Thorac Cardiovasc Surg. 2013;145:140-8; discussion 8-9.

14. Proudfit WL, Bruschke AV, Sones FM Jr. Natural history of obstructive coronary artery disease: ten-year study of 601 nonsurgical cases. Prog Cardiovasc Dis. 1978:21:53-78.

15. Synnergren MJ, Ekroth R, Oden A, Rexius H, Wiklund L. Incomplete revascularization reduces survival benefit of coronary artery bypass grafting: role of off-pump surgery. J Thorac Cardiovasc Surg. 2008;136:29-36.

16. Raza S, Sabik JF III, Masabni K, Ainkaran P, Lytle BW, Blackstone EH. Surgical revascularization techniques that minimize surgical risk and maximize late survival after coronary artery bypass grafting in patients with diabetes mellitus. J Thorac Cardiovasc Surg. 2014;148:1257-64; discussion 64-6.

17. Sabik JF III, Lytle BW, Blackstone EH, Khan M, Houghtaling PL, Cosgrove DM Does competitive flow reduce internal thoracic artery graft patency? Ann Thorac Surg. 2003;76:1490-6; discussion 7.

18. Toth G, De Bruyne B, Casselman F, De Vroey F, Pyxaras S, Di Serafino L, et al Fractional flow reserve-guided versus angiography-guided coronary artery bypass graft surgery. Circulation. 2013;128:1405-11.

19. Pijls NH, van Son JA, Kirkeeide RL, De Bruyne B, Gould KL. Experimental basis of determining maximum coronary, myocardial, and collateral blood flow by pressure measurements for assessing functional stenosis severity before and after percutaneous transluminal coronary angioplasty. Circulation. 1993;87:1354-67.

20. Lazar HL. Fractional flow-guided coronary artery bypass grafting: a word of caution. Circulation. 2013;128:1393-5.

Key Words: coronary artery, moderate stenosis, coronary artery bypass grafting, long-term survival, ischemia-guided approach, fractional flow reserve 


\section{APPENDIX E1. VARIABLES CONSIDERED IN MULTIVARIABLE ANALYSES \\ Demography}

Age (y), sex, race (white, black, other), weight ( $\mathrm{kg}$ ), height $(\mathrm{cm})$, weight/height ratio, body surface area $\left(\mathrm{m}^{2}\right)$, body mass index $\left(\mathrm{kg} \cdot \mathrm{m}^{-2}\right)$

\section{Status/Symptoms}

New York Heart Association functional class (I-IV), emergency operation

\section{Cardiac comorbidity}

Prior myocardial infarction, atrial fibrillation or flutter, heart failure

\section{Noncardiac comorbidity}

Treated diabetes, peripheral vascular disease, carotid disease, hypertension, history of smoking, prior stroke, cholesterol $\left(\mathrm{mg} \cdot \mathrm{dL}^{-1}\right)$, triglycerides $\left(\mathrm{mg} \cdot \mathrm{dL}^{-1}\right)$, creatinine $\left(\mathrm{mg} \cdot \mathrm{dL}^{-1}\right)$

\section{Coronary anatomy}

Number of coronary systems diseased ( $\geq 50 \%$ stenosis), left anterior descending (LAD) disease $(\geq 50 \%$, moderate
[50\%-69\%], severe [ $\geq 70 \%]$ ), left circumflex (LCx) system disease $(\geq 50 \%$, moderate $[50 \%-69 \%]$, severe $[\geq 70 \%]$ ), right coronary artery (RCA) system disease ( $\geq 50 \%$, moderate $[50 \%-69 \%]$, severe $[\geq 70 \%]$ ), diagonal (Dg) disease $(\geq 50 \%$, moderate $[50 \%-69 \%]$, severe $[\geq 70 \%]$ ), location of moderate coronary artery disease (CAD; LAD, Dg, LCx, RCA)

\section{Coronary Artery Bypass Grafting Procedures}

Number of internal thoracic artery (ITA) grafts used to graft severely stenosed arteries (none, 1,2), conduit used to bypass moderate CAD (none, ITA, saphenous vein, radial artery, other), graft locations (LAD, LAD diagonals, $\mathrm{LCx}$ territory, RCA territory), interaction terms for conduit used to bypass moderate $\mathrm{CAD}$ in each location (none, ITA, saphenous vein)

\section{Support}

Cardiopulmonary bypass (off-pump vs on-pump), bypass time (min)

\section{Experience}

Date of operation (years since January 1, 1972) 


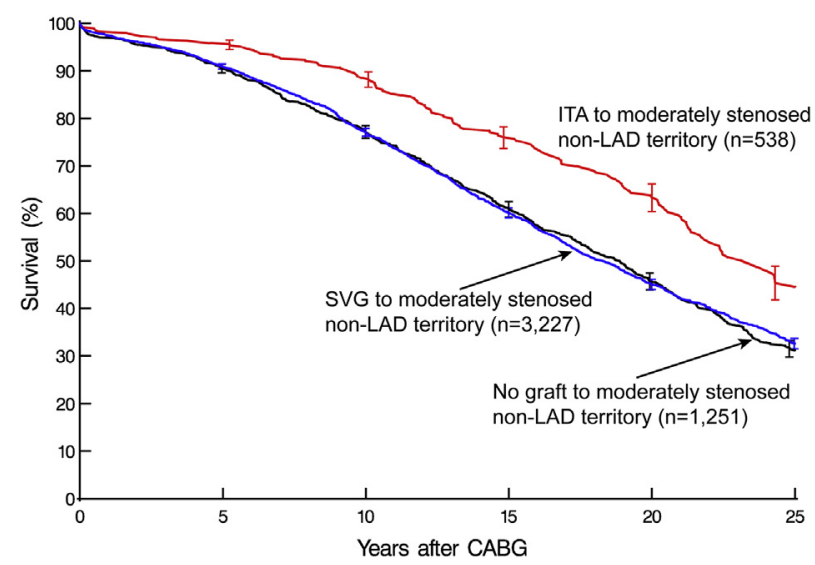

FIGURE E1. Survival advantage of internal thoracic artery (ITA) grafting of a moderately stenosed non-left anterior descending coronary artery $(L A D)$ after ITA grafting of a severely stenosed LAD. Format is as in Figure 1. $S V G$, Saphenous vein graft; $C A B G$, coronary artery bypass grafting.

TABLE E1. Conduits placed to each moderately stenosed coronary artery: No. (\%)

\begin{tabular}{lccccc}
\hline & Overall, $\mathbf{n}=\mathbf{8 5 3 1}$ & LAD, $\mathbf{n}=\mathbf{1 5 8 3}$ & $\mathbf{R C A}, \mathbf{n}=\mathbf{2 5 9 9}$ & $\mathbf{L C x}, \mathbf{n}=\mathbf{2 7 1 4}$ & Diagonal, $\mathbf{n}=\mathbf{1 6 3 5}$ \\
\hline Not bypassed & $1933(23)$ & $121(7.6)$ & $654(25)$ & $559(21)$ & $599(37)$ \\
ITA graft & $1806(21)$ & $1167(74)$ & $121(4.7)$ & $313(11)$ & $205(12)$ \\
SV graft & $4625(54)$ & $291(18)$ & $1774(68)$ & $1757(65)$ & $803(49)$ \\
Other graft & $167(2.0)$ & $4(0.25)$ & $50(1.9)$ & $85(3.1)$ & $28(1.7)$ \\
\hline
\end{tabular}

$L A D$, Left anterior descending coronary artery; $R C A$, right coronary artery; $L C x$, left circumflex coronary artery; ITA, internal thoracic artery; $S V$, saphenous vein. 
TABLE E2. Risk factors for mortality after CABG with 1 system of moderate CAD $(n=8531)$ : reference group $=$ moderate $\mathrm{CAD}$ grafted versus nongrafted

\begin{tabular}{|c|c|c|c|}
\hline Factor & Estimate $\pm \mathrm{SE}$ & $\boldsymbol{P}$ & $\begin{array}{c}\text { Reliability } \\
\% *\end{array}$ \\
\hline \multicolumn{4}{|l|}{ Early phase } \\
\hline \multicolumn{4}{|l|}{ Demography } \\
\hline Older age $\dagger$ & $0.462 \pm 0.089$ & $<.0001$ & 68 \\
\hline Lower BMI $\ddagger$ & $0.324 \pm 0.104$ & .002 & 55 \\
\hline \multicolumn{4}{|l|}{ Status/symptoms } \\
\hline Emergency operation & $0.995 \pm 0.331$ & .002 & 63 \\
\hline NYHA class II & $-0.342 \pm 0.136$ & .010 & 90 \\
\hline \multicolumn{4}{|l|}{ Comorbidities } \\
\hline Peripheral vascular disease & $0.669 \pm 0.156$ & $<.0001$ & 72 \\
\hline Prior stroke & $0.564 \pm 0.213$ & .008 & 54 \\
\hline Heart failure & $0.808 \pm 0.188$ & $<.0001$ & 50 \\
\hline Treated diabetes & $0.471 \pm 0.151$ & .002 & 51 \\
\hline \multicolumn{4}{|l|}{ Procedural } \\
\hline $\begin{array}{l}\text { No. of ITAs used to graft } \\
\text { severely stenosed }(\geq 70 \%) \\
\text { coronary arteries }\end{array}$ & $-0.294 \pm 0.113$ & .009 & 91 \\
\hline Moderate CAD bypassed & $-0.128 \pm 0.135$ & .3 & Forced in \\
\hline \multicolumn{4}{|l|}{ Late phase } \\
\hline \multicolumn{4}{|l|}{ Demography } \\
\hline Older age $\S$ & $1.27 \pm 0.044$ & $<.0001$ & 100 \\
\hline Weight $\|$ & $0.224 \pm 0.057$ & $<.0001$ & 67 \\
\hline \multicolumn{4}{|l|}{ Status/symptoms } \\
\hline Prior myocardial infarction & $0.166 \pm 0.032$ & $<.0001$ & 100 \\
\hline NYHA class III/IV & $0.073 \pm 0.032$ & .02 & 76 \\
\hline \multicolumn{4}{|l|}{ Comorbidities } \\
\hline Peripheral vascular disease & $0.316 \pm 0.056$ & $<.0001$ & 100 \\
\hline Prior stroke & $0.279 \pm 0.089$ & .002 & 93 \\
\hline Heart failure & $0.248 \pm 0.090$ & .006 & 98 \\
\hline Treated diabetes & $0.447 \pm 0.049$ & $<.0001$ & 100 \\
\hline Elevated triglycerides & $0.089 \pm 0.040$ & .02 & 80 \\
\hline History of smoking & $0.299 \pm 0.034$ & $<.0001$ & 100 \\
\hline \multicolumn{4}{|l|}{ Coronary anatomy } \\
\hline No. of systems diseased $\uparrow$ & $0.114 \pm 0.031$ & .0003 & 95 \\
\hline \multicolumn{4}{|l|}{ Procedural } \\
\hline $\begin{array}{l}\text { No. of ITAs used to graft } \\
\text { severely stenosed }(\geq 70 \%) \\
\text { coronary arteries }\end{array}$ & $-0.224 \pm 0.030$ & $<.0001$ & 91 \\
\hline Moderate CAD bypassed & $-0.114 \pm 0.038$ & .003 & Forced in \\
\hline
\end{tabular}

$S E$, Standard error; $B M I$, body mass index; NYHA, New York Heart Association; ITA, internal thoracic artery; $C A D$, coronary artery disease. *Percent of times factor appeared in 500 bootstrap models. $\dagger \operatorname{Exp}($ age/50), exponential transformation. $\ddagger(25 / \mathrm{BMI})^{2}$, inverse squared transformation. $\S(\mathrm{Age} / 50)^{2}$, squared transformation. $\|(\mathrm{kg} / 80)^{2}$, squared transformation. $\uparrow 1,2$, or 3 systems, $\geq 50 \%$ stenosis.
TABLE E3. Risk factors for mortality after CABG with 1 system of moderate CAD $(n=8531)$ : reference group $=$ ITA grafting versus SV grafting versus nongrafted

\begin{tabular}{|c|c|c|c|}
\hline Factor & Estimate $\pm \mathrm{SE}$ & $\boldsymbol{P}$ & $\begin{array}{c}\text { Reliability, } \\
\% *\end{array}$ \\
\hline \multicolumn{4}{|l|}{ Early phase } \\
\hline \multicolumn{4}{|l|}{ Demography } \\
\hline Older age $\dagger$ & $0.399 \pm 0.087$ & $<.0001$ & 68 \\
\hline Lower $\mathrm{BMI}_{\ddagger}^{\dagger}$ & $0.320 \pm 0.102$ & .002 & 55 \\
\hline \multicolumn{4}{|l|}{ Status/symptoms } \\
\hline NYHA class II & $-0.331 \pm 0.135$ & .01 & 90 \\
\hline \multicolumn{4}{|l|}{ Comorbidities } \\
\hline Peripheral vascular disease & $0.682 \pm 0.154$ & $<.0001$ & 72 \\
\hline Prior stroke & $0.598 \pm 0.214$ & .005 & 54 \\
\hline Heart failure & $0.824 \pm 0.187$ & $<.0001$ & 50 \\
\hline Treated diabetes & $0.514 \pm 0.151$ & .0006 & 51 \\
\hline \multicolumn{4}{|l|}{ Procedural } \\
\hline $\begin{array}{l}\text { No. of ITAs used to graft } \\
\text { severely stenosed }(\geq 70 \%) \\
\text { coronary arteries }\end{array}$ & $-0.48 \pm 0.118$ & $<.0001$ & 91 \\
\hline ITA graft to moderate CAD & $-0.76 \pm 0.20$ & .0001 & Forced in \\
\hline SV graft to moderate CAD & $0.0088 \pm 0.034$ & .8 & Forced in \\
\hline \multicolumn{4}{|l|}{ Late phase } \\
\hline \multicolumn{4}{|l|}{ Demography } \\
\hline Older age $\S$ & $1.26 \pm 0.043$ & $<.0001$ & 100 \\
\hline Weight $\|$ & $0.234 \pm 0.058$ & $<.0001$ & 67 \\
\hline \multicolumn{4}{|l|}{ Status/symptoms } \\
\hline Prior myocardial infarction & $0.163 \pm 0.032$ & $<.0001$ & 100 \\
\hline NYHA class III/IV & $0.069 \pm 0.033$ & .03 & 76 \\
\hline \multicolumn{4}{|l|}{ Comorbidities } \\
\hline Peripheral vascular disease & $0.308 \pm 0.057$ & $<.0001$ & 100 \\
\hline Prior stroke & $0.285 \pm 0.092$ & .002 & 93 \\
\hline Heart failure & $0.233 \pm 0.093$ & .01 & 98 \\
\hline Treated diabetes & $0.448 \pm 0.049$ & $<.0001$ & 100 \\
\hline Elevated triglycerides & $0.088 \pm 0.041$ & .03 & 80 \\
\hline History of smoking & $0.307 \pm 0.034$ & $<.0001$ & 100 \\
\hline \multicolumn{4}{|l|}{ Coronary anatomy } \\
\hline No. of systems diseased $\uparrow$ & $0.117 \pm 0.032$ & .0002 & 95 \\
\hline \multicolumn{4}{|l|}{ Procedural } \\
\hline $\begin{array}{l}\text { No. of ITAs used to graft } \\
\text { severely stenosed } \\
(\geq 70 \%) \text { coronary } \\
\text { arteries }\end{array}$ & $-0.265 \pm 0.032$ & $<.0001$ & 91 \\
\hline ITA graft to moderate CAD & $-0.242 \pm 0.051$ & $<.0001$ & Forced in \\
\hline SV graft to moderate CAD & $-0.047 \pm 0.039$ & .2 & Forced in \\
\hline
\end{tabular}

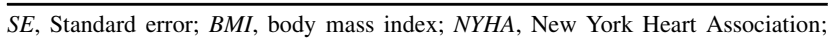
$I T A$, internal thoracic artery; $C A D$, coronary artery disease; $S V$, saphenous vein. *Percentage of times factor appeared in 500 bootstrap models. $\dagger \operatorname{Exp}($ age/50), exponential transformation. $\ddagger(25 / \mathrm{BMI})^{2}$, inverse squared transformation. $\S$ (age/ $50)^{2}$, squared transformation. $\|(\mathrm{kg} / 80)^{2}$, squared transformation. $\uparrow 1,2$, or 3 systems, $\geq 50 \%$ stenosis. 